\title{
Medical corruption in the UK
}

\author{
Fiona Godlee editor in chief, The BMJ
}

Last year The BMJ launched an international campaign against corruption in healthcare. A single article was the spark: a personal view about the endemic culture of kickbacks to doctors in India (doi:10.1136/bmj.g3169). The campaign received widespread support from Indian doctors and the media, and it seems to have led to some positive change, if not yet enough. In an unprecedented move India's then health minister acknowledged that corruption was a big problem. The government set up a special committee and has banned gifts to doctors and conference sponsorship by drug companies. The Indian Medical Association is working on a new code of medical ethics for private hospitals. And the Medical Council of India, which regulates India's doctors, has committed itself to act against any doctors reported to have received kickbacks.

A linked editorial made it clear that India was not alone in having a deeply embedded culture in medicine of tolerance to and even promotion of corruption (doi:10.1136/bmj.g3169). If anyone doubted this, recent news from the United States suggested that healthcare corruption was equally endemic there. On top of evidence that the US loses billions of dollars each year to medical embezzlement (http://econ.st/1BuAiFW), high profile cases are now making clear the mechanisms and the human cost. Six doctors in Chicago are currently being prosecuted for allegedly taking kickbacks. Their alleged crimes includes referring patients to hospital who didn't need admission and performing unnecessary but lucrative tracheotomies, leading to avoidable deaths (doi:10.1136/bmj.h22).

Nor, sadly, is the United Kingdom immune. A $B M J$ investigation published this week reports clear evidence of UK doctors receiving covert financial inducements to refer patients to private hospital groups. Some London based doctors have benefited by tens, sometimes hundreds, of thousands of pounds (doi:10.1136/ bmj.h396).

No doubt the beneficiaries will include some of the pillars of Britain's medical establishment. Also no doubt most of those involved will believe that they themselves cannot be bought. But even if that were true, it is the perception of conflicts of interest that matters, as well as the reality. How many doctors enjoying free use of consulting rooms will have explained to a patient: "I am referring you to this hospital (or moving you to this other hospital) because I have a contract with them that rewards me for doing so"?

Some of the beneficiaries might argue that the UK's General Medical Council has no specific guidance on private sector inducements, and they would be right. The GMC's failure to provide such guidance, and its apparent reluctance to act on information about kickbacks that was presented to it in 2012, are the focus of a linked editorial (doi:10.1136/bmj.h474). But even without clear guidance or action from the GMC, it seems obvious that referral for any reason other than because the patient's best interests require it contravenes professional ethics. Gornall reports that some doctors were offered inducements but declined for this reason. And one notable private hospital group keeps well away from inducements, preferring to compete on the quality of the service it provides.

The profession must take the lead to protect patients and maintain public trust. The GMC should act, and a public register of UK doctors' financial interests is long overdue.

Cite this as: BMJ 2015;350:h506

๑ BMJ Publishing Group Ltd 2015 